\title{
PENGARUH PEMBERIAN BAHAN ORGANIK KIRINYU ( Chromolaena Odorata)TERHADAP PERTUMBUHAN DAN HASIL SAWI (Brasica Juncea ) DI KAWASAN AGROECOTOURISM
}

\author{
Agustinus J. P. Ana Saga ${ }^{1}$ dan Murdaningsih ${ }^{2}$ \\ Program Studi Agroteknologi, Fakultas Pertanian Universitas Flores \\ Agustinus_saga@yahoo.co.id
}

\section{ABSTRACT \\ THE EFFECTS OF ORGANIC MATERIAL (Chromolaena odorata) FOR GROWTH AND DEVELOPMENT OF INDIAN MUSTARD (Brassica juncea) IN AGROECOTOURIM AREA}

This study aimed to explore the effect of Siam weed (Chromolaena odorata) green manure application on the growth and development of mustard (Brassica juncea) in Kelimutu National Park, Indonesia. The study was carried out between September and November 2010 in Ende district on the island of Flores, Indonesia, at an altitude of 1500 to 1730 meters above sea level.

This study used a randomized block design with four treatments: $\mathrm{K}_{0}$ : No Siam weed aplication, $\mathrm{K}_{1}: 5$ tons $/ \mathrm{ha}$ Siam weed $(2.8 \mathrm{~kg} / \mathrm{plot}), \mathrm{K}_{2}: 10$ tons $/ \mathrm{ha}$ Siam weed $(5.6 \mathrm{~kg} / \mathrm{plots}), \mathrm{K}_{3}: 15$ tons $/$ ha Siam weed $(8.4 \mathrm{~kg} / \mathrm{plot}), \mathrm{K}_{4}: 20$ tons $/$ ha Siam weed $(11.2 \mathrm{~kg} / \mathrm{plot})$. Researchers observed plant characteristics (plant height, leaf area, wet weight and number of leaves) and soil fertility indicators (Organic carbon). Plant organic matter was ground and subsequently analyzed for nutrients using a randomized block design along with lab analysis for soil fertility.

The results of this study showed that the application of Siam weed organic matter had no significant effect on mustard plant height, leaf number, leaf area, or wet weight. However, it was found that organic matter application did have a significant effect on soil fertility indicators (organic carbon), and caused an increase in soil organic matter content.

Key words: Chromolaena odorata, Brassia juncea, Kelimutu National Park, soil health, soil organic material

\section{PENDAHULUAN}

Indonesia memiliki iklim tropis, hal tersebut merupakan modal sumber daya alam yang luar biasa dimana berbagai sayuran, buah dan tanaman pangan hingga beraneka macam bunga dapat dibudidayakan sepanjang tahun. Survey BPS (2000) menunjukkan bahwa produksi sayuran di Indonesia, khususnya sawi adalah 326.693 ton dengan total area seluas $291.192 \mathrm{Ha}$ (Anonim, 2008).
Tanaman sawi dapat tumbuh dengan keadaan suhu berkisar antara 20 ${ }^{\circ} \mathrm{C}-30{ }^{\circ} \mathrm{C}$, kebutuhan sinar matahari tinggi berkisar antara $400-800$ footcandles, dan kelembaban tinggi berkisar antara $>60 \%$ (Nazarudin,2003) sehingga dapat diusahakan dari dataran rendah maupun dataran tinggi serta berpotensi untuk dikomersilkan, mengingat tanaman sawi yang berumur pendek, dengan umur panen yakni satu bulan (Anonim, 2008), sehingga memudahkan petani untuk 
membudidayakan jenis sayuran ini karena tidak membutuhkan waktu lama dan mendapat hasil yang lebih cepat sehingga menguntungkan secara ekonomi

Nilai ekonomis tanaman sawi adalah pada daun, sehingga untuk menghasilkan kualitas daun yang baik maka tanaman tersebut banyak membutuhkan unsur $\mathrm{N}$ untuk menghasilkan kuantitas dan kualitas hasil yang tinggi (Anonim,2008), dengan kebutuhan unsur $\mathrm{N}$ maksimal perhektar adalah $300-400 \mathrm{~kg}$ pupuk urea maka untuk mengimbangi hal tersebut perlu pemberian input luar, diantaranya pemberian bahan organik yang berasal dari tanaman liar yakni kirinyu (Cromolaenaodorata) yang sangat berpotensi untuk meningkatkan kesuburan tanah yakni sifat fisik diantaranya warna tanah, tekstur tanah, struktur tanah, dan porositas tanah. Sedangkan sifat kimia adalah meningkatkan kapasitas tukar kation (KTK), dapat meningkatkan dan menurunkan $\mathrm{pH}$ tanah, meningkatkan unsur hara tanah seperti N, P, K (Kurnianto.M, 2008).

Mengingat petani di lapang tidak terbiasa mengembalikan unsur hara yang telah terbawa atau terserap oleh tanaman yang mereka budidayakan, yang menyebapkan unsur hara pada tanah dengan sendirinya akan berkurang dan kemudian akan habis. dan akhirnya akan berdampak pada produksi tanaman dan produktivitas tanah, (Kurnianto.M,2008) penelitian yang berkaitan dengan pemanfaatan tanaman liar kirinyu, pada kawasan Agroecotourism dianggap perlu karena mengingat tanaman kirinyu sangat besar populasinya pada lokasi tersebut dan belum dimanfaatkan, selain itu keberadaan kirinyu dapat merugikan tanaman lain karena mengandung zat alelopati (Kurnianto.M, 2008)
Tanaman liar kirinyu oleh para petani pada lokasi penelitian dianggap sebagai gulma yang dapat merugikan tanaman yang dibudidayakan.Biomasa kirinyu mempunyai kandungan hara yang cukup tinggi,dimana mengandung hara Nitrogen $2.65 \%$ N, Fosfor $0.53 \% \mathrm{P}$ dan Kalium 1.9\% K sehingga biomasa kirinyu merupakan sumber bahan organik yang potensial untuk perbaikan kesuburan tanah (Atmojo, 2007), biomassa tanaman merupakan sumber pupuk organik yang murah, juga berfungsi untuk mempertahankan kandungan bahan organik dan kesuburan tanah. Bahan organik akan mendorong kehidupan organisme, tidak hanya organisme heterotrof yang bertanggung jawab pada proses dekomposisi tetapi juga azobakter mikroorganisme penambat nitrogen. Bahan organik memasok nitrogen dan sulfur dan setengah fosfor yang diserap tanaman (Susanto, 2002 dalam Purba, 2009).

Sumber bahan organik terdiri dari daun-daunan yang mudah membusuk dalam tanah. Daun-daunan dapat langsung dimasukkan kedalam tanah sebagai pupuk hijau. Sumber bahan organik yang ada di lapang cukup banyak namun terkadang kita belum tahu atau tidak biasa menggunakannya, salah satu diantaranya adalah kirinyu (Cromolaena odorata) (Setyamidjaja, 1986 dan Purba 2009)

Jenis tanah yang berada pada lokasi penelitian termasuk lempung berpasir dengan sifat - sifatnya kemampuan menahan air rendah, kemampuan menyimpan unsur hara sangat kecil, dan airasenya baik. Hal ini yang kemudian mendorong peneliti guna melakukan penelitian dengan pemanfaatan bahan organik kirinyu untuk memperbaiki sifat fisik, kimia dan biologi tanah pada lokasi penelitian, dan sebagai indikator kesuburan tanah dalam penelitian ini, dapat dilihat dari kandungan Bahan 
Organik tanah dan kandungan C Organik tanah, dimana jika kandungan Bahan Organik dan C - Organik tanah dibawah $1 \%$ maka unsur hara lain seperti Nitrogen, Pospor, dan Kalium juga berkurang maka perlu penambahan input luar yang dapat meningkatkan kandungan Bahan Organik dan C Organik tanah. Kandungan bahan organik dan kandungan C - Organik tanah ideal berkisar antara $3-5 \%$ dan jika rendah maka perlu penambahan Bahan Organik yang tepat (Anonim, 2010).

\section{METODE PENELITIAN}

Penelitian ini dilakukan di kawasan Agroecoteurism Kelimutu, Kecamatan Kelimutu, Kabupaten Ende, Flores, NTT. Ketinggian tempat antara $1500-$ $1731 \mathrm{dpl}$, temperatur udara berkisar antara $25^{\circ} \mathrm{C}-31^{\circ} \mathrm{C}$, serta jenis tanah lempung berpasir. Penelitian ini dilaksanakan dari bulan September sampai November 2010

Alat yang digunakan dalam penelitian ini adalah, mesin pencacah kirinyu, tali rafia, meteran, parang, cangkul, garu/sisir, karung, alat tulis menulis, timbangan, patok perlakuan, dan mistar.

Bahan yang digunakan meliputi, kirinyu, pupuk kandang (kotoran ayam), dan benih sawi (caisin)

Rancangan percobaan yang digunakan adalah Rancangan Acak Kelompok (RAK) dengan 5 perlakuan yaitu: Ko : kontrol (tanpa menggunakan kirinyu)

$$
\begin{aligned}
& \mathrm{K} 1: 5 \text { ton kirinyu }\left(0,5 \mathrm{~kg} / \mathrm{m}^{2} \times 5,6 \mathrm{~m}^{2}\right) \\
&=2,8 \mathrm{~kg} / \text { petak } \\
& \mathrm{K} 2: 10 \text { ton kirinyu }\left(1 \mathrm{~kg} / \mathrm{m}^{2} \times 5,6 \mathrm{~m}^{2}\right) \\
&=5,6 \mathrm{~kg} / \text { petak } \\
& \mathrm{K} 3: \begin{aligned}
15 \text { ton kirinyu }\left(1,5 \mathrm{~kg} / \mathrm{m}^{2} \times 5,6\right. \\
\left.\mathrm{m}^{2}\right)=8,4 \mathrm{~kg} / \mathrm{petak}
\end{aligned} \\
& \mathrm{K} 4: \begin{array}{l}
20 \text { ton } \mathrm{kirinyu}\left(2 \mathrm{~kg} / \mathrm{m}^{2} \times 5,6 \mathrm{~m}^{2}\right) \\
=11,2 \mathrm{~kg} / \text { petak }
\end{array}
\end{aligned}
$$

Setiap perlakuan diulangi 4 kali sehingga secara keseluruhan terdapat 20 satuan percobaan.

Persiapan lahan adalah penetapan lahan penelitian. Kegiatan ini mencakup penataan lokasi, analisis jenis tanah dan $\mathrm{pH}$ tanah serta pengolahan lahan. Tanah dicangkul, diolah sampaigembur, sesudah itu dibuat bedengan dengan ukuran lebar $200 \mathrm{~cm}$, panjang $280 \mathrm{~cm}(56000 \mathrm{~cm} 2)$ dan tinggi $20 \mathrm{~cm}$ serta jarak antar bedengan $40 \mathrm{~cm}$.

Pupuk yang digunakan, dalam penelitian ini adalah pupuk dasar yang berasal dari kotoran unggas (Ayam) dengan kebutuhan maksimal 15 ton/ha sedangkan dalam penelitian ini pupuk kandang yang digunakan sebanyak 2 ton $/$ ha $\left(0,2 \mathrm{~kg} / \mathrm{m}^{2} \times 5,6\right)=1,12 \mathrm{~kg} /$ petak dengan tujuan agar pemberian pupuk kandang tidak memberikan pengaruh terhadap pertumbuhan dan hasil tanaman sawi. Masing - masing bedengan diberikan bahan organik kirinyu dengan dosis sesuai perlakuan penelitian, dan diberikan pada saat pengolahan tanah sehingga tercampur merata.

Tanah tempat penyemaian benih diolah sampai gembur kemudian dibuat bedengan sesuai dengan kebutuhan. Benih disebar merata kemudian ditutup tanah halus. Tempat bedengan dibuat atap untuk mengurangi penyinaran matahari langsung. Persemaian disiram setiap pagi dan sore hari. Benih akan berkecambah setelah $3-4$ hari. Benih yang berumur $7-10$ hari atau telah mempunyai $3-4$ helai daun siap untuk dipindahkan dan ditanam pada lokasi penelitian

Benih sawi yang telah siap tanam, ditanam pada bedengan yang telah siap untuk ditanami. Jarak tanam yang digunakan adalah $25 \times 25 \mathrm{~cm}$.

Pemeliharaan tanaman sawi meliputi penyulaman dengan mengganti 
tanaman sawi dengan cara manual. Penyiraman tanaman sawi setiap hari yaitu pagi dan sore hari dilaksanakan selama tanaman sawi ditanam sampai panenPenyiangan, dilakukan $2-4$ kali selama masa pertanaman, disesuaikan dengan kondisi keberadaan gulma pada bedengan penanaman. Penyiangan dilakukan 1 atau 2 minggu setelah tanam dan dilakukan sekalian dengan penggemburan serta pembumbuna.

Pengendalian hama dan penyakit dilakukan dengan cara manual yaitu dengan mencabut tanaman yang terserang hama dan penyakit sehingga tidak menyebar ke tanaman lain

Selama penelitian dilaksanakan, variabel yang diamati dua minggu setelah tanam dan dilanjutkan dengan interval pengamatan 5 hari yaitu:

1. Tinggi Tanaman $(\mathrm{cm})$.

Tinggi tanaman diukur dari permukaan tanah hingga ujung daun ketika di tangkup/disatukan. Pengukuran dilakukan pada umur dua minggu setelah tanam dengan interval lima hari yaitu :14 hst, 19 hst, 24 hst, 29 hst.

2. Jumlah Daun (helai), Dihitung semua helaian daun pada semua sampel yang berjumlah 16 dan dibagi dengan jumlah sampelpengukuran dilakukan pada umur dua minggu setelah tanam kemudian dilanjutkan dengan interval lima hari dengan selang waktu yaitu : 14 hst, 19 hst, 24 hst, 29 hst.

3. Luas Daun, Diukur dengan menggunakan metode panjang $\mathrm{x}$ lebar x kostanta, untuk nilai konstanta diperoleh dengan cara menggunakan dua metode pembanding yakni metode panjang $\mathrm{X}$ lebar dan metode grafimetri yakni berat kertas replika daun dibagi berat total kertas dikali luas total kertas, kertas yang digunakan adalah kertas HVS. pengukuran dilakukan pada umur dua minggu setelah tanam kemudian dilanjutkan dengan interval lima hari yaitu : 14 hst, 19 hst24 hst, 29 hst.

4. Bobot segar tanaman (g), Penimbangan dilakukan pada saat panen. Dengan cara berat sampel dari masing - masing petak perlakuanditimbang, kemudian dibagi dengan jumlah sampel dari masing - masing petak dan dirata - ratakan. Perhitungannya dengan mengguakan rumus :

Bobot segar $=\underline{\text { Berat sampel dalam petak }}$ Jml. Sampel dalam petak

5. Kandungan Bahan Organik dan Kandungan C - Organik tanah, Pengamatan tanah dilakukan dengan mengambil sampel tanah dari masing - masing perlakuan sebanyak 500 g. kemudian dianalisis untuk mengetahui kandungan C - organik, dan Bahan Organik dengan menggunakan metode retjal

\section{Analisis Data}

Data hasil pengamatan dianalisis dengan analisis sidik ragam apabila perlakuan menunjukan pengaruh nyata terhadap variabel yang diamati, maka dilanjutkan dengan uji BNT taraf $5 \%$ (Gomez, 1995).

\section{HASIL PEMBAHASAN}

Hasil analisis sidik ragam menunjukan bahwa pemberian Bahan Organik Kirinyu tidak memberikan pengaruh nyata terhadap Tinggi Tanaman, Jumlah Daun, Luas Daun dan Bobot Basah pada semua umur pengamatan $14,19,24,29$ HST.

Hasil penelitian yang menunjukan bahwa pemberian bahan organik kirinyu tidak berpengaruh nyata pada pertumbuhan tanaman sawi baik terhadap tinggi tanaman, jumlah daun, luas daun, dan bobot basah dari tanaman sawi.Apa bila dilihat dari kebutuhan hara tanaman 
sawi adalah $300-400 \mathrm{~kg} / \mathrm{ha}(414 \mathrm{~N} \mathrm{~kg})$ sedangkan kirinyu yang diberikan 5 20 ton/ha $(184000 \mathrm{~N} \mathrm{~kg})$ ternyata pemberian bahan organik kirinyu melebihi kebutuhan $\mathrm{N}$ untuk tanaman sawi sehingga tidak berpengaruh nyata pada pertumbuhannya. Hal lain juga diduga disebabkan oleh adanya proses dekomposisi bahan organik kirinyu belum terjadi secara maksimal, yang dapat menghasilkan unsur hara baik hara makro maupun mikro yang dibutuhkan tanaman diantaranya adalah $\mathrm{N}, \mathrm{P}$, dan $\mathrm{K}$ sehingga belum belum dapat dimanfaat kan oleh tanaman, karena umur panen tanaman sawi berkisar satu bulan. Hasil penelitian ini didukung oleh pandapat Kardin Darjat, (2010) yang menyatakan bahwa proses dekomposisi kirinyu terjadi $3-4$ bulan. Sedangkan umur tanaman sawi hanya satu bulan (Anonim, 2008). Faktor lain yang diduga juga adalah curah hujan, pada saat penelitian terjadi hujan dengan intensitas tinggi sehingga pertumbuhan tanaman sawi tidak optimal. Keadaan ini karena tanaman sawi tidak menghendaki curah hujan yang tinggi (Margiato Eko,2007).

Tabel 4.1 Rerata Tinggi tanaman, Jumlah daun, dan Luas daun tanaman Sawi akibat pemberian Bahan Organik Kirinyu pada berbagai umur pengamatan

\begin{tabular}{|c|c|c|c|c|c|}
\hline & \multirow[t]{2}{*}{ Variabel } & \multicolumn{4}{|c|}{ Waktu Pengamatan } \\
\hline & & $14 \mathrm{hst}$ & $19 \mathrm{hst}$ & $24 \mathrm{hst}$ & $29 \mathrm{hst}$ \\
\hline \multirow[t]{6}{*}{1} & Tinggi Tanaman $(\mathrm{cm})$ : & & & & \\
\hline & - $\mathrm{BO} 0$ & $5,55 \mathrm{TN}$ & $6,67 \mathrm{TN}$ & $8,72 \mathrm{TN}$ & $13,35 \mathrm{TN}$ \\
\hline & - $\mathrm{BO} 1$ & $5,86 \mathrm{TN}$ & $6,81 \mathrm{TN}$ & $9,10 \mathrm{TN}$ & $13,51 \mathrm{TN}$ \\
\hline & - $\mathrm{BO} 2$ & $5,57 \mathrm{TN}$ & $6,35 \mathrm{TN}$ & $8,45 \mathrm{TN}$ & $12,14 \mathrm{TN}$ \\
\hline & - $\mathrm{BO} 3$ & $6,34 \mathrm{TN}$ & $6,79 \mathrm{TN}$ & $8,74 \mathrm{TN}$ & $13,02 \mathrm{TN}$ \\
\hline & - $\mathrm{BO} 4$ & $6,48 \mathrm{TN}$ & $7,35 \mathrm{TN}$ & $9,46 \mathrm{TN}$ & $13,64 \mathrm{TN}$ \\
\hline \multirow[t]{6}{*}{2} & Jumlah Daun & & & & \\
\hline & - $\mathrm{BO} 0$ & $3,80 \mathrm{TN}$ & $4,68 \mathrm{TN}$ & $5,23 \mathrm{TN}$ & $5,42 \mathrm{TN}$ \\
\hline & - $\mathrm{BO} 1$ & $3,87 \mathrm{TN}$ & $4,90 \mathrm{TN}$ & $5,28 \mathrm{TN}$ & $5,28 \mathrm{TN}$ \\
\hline & - $\mathrm{BO} 2$ & $3,70 \mathrm{TN}$ & $4,48 \mathrm{TN}$ & $4,90 \mathrm{TN}$ & $4,90 \mathrm{TN}$ \\
\hline & - $\mathrm{BO} 3$ & $3,87 \mathrm{TN}$ & $4,32 \mathrm{TN}$ & $4,95 \mathrm{TN}$ & $5,10 \mathrm{TN}$ \\
\hline & - $\mathrm{BO} 4$ & $3,82 \mathrm{TN}$ & $4,73 \mathrm{TN}$ & $5,43 \mathrm{TN}$ & $5,32 \mathrm{TN}$ \\
\hline \multirow[t]{6}{*}{3} & Luas Daun $\left(\mathrm{cm}^{2}\right)$ : & & & & \\
\hline & - $\mathrm{BO} 0$ & $2,74 \mathrm{TN}$ & $4,35 \mathrm{TN}$ & $7,78 \mathrm{TN}$ & $16,43 \mathrm{TN}$ \\
\hline & - $\mathrm{BO} 1$ & $3,16 \mathrm{TN}$ & $4,44 \mathrm{TN}$ & $7,28 \mathrm{TN}$ & $17,52 \mathrm{TN}$ \\
\hline & - $\mathrm{BO} 2$ & $2,81 \mathrm{TN}$ & $4,12 \mathrm{TN}$ & $6,63 \mathrm{TN}$ & $16,58 \mathrm{TN}$ \\
\hline & - $\mathrm{BO} 3$ & $3,28 \mathrm{TN}$ & $3,17 \mathrm{TN}$ & $6,98 \mathrm{TN}$ & $16,93 \mathrm{TN}$ \\
\hline & - $\mathrm{BO} 4$ & $3,69 \mathrm{TN}$ & $5,05 \mathrm{TN}$ & $9,25 \mathrm{TN}$ & $19,41 \mathrm{TN}$ \\
\hline
\end{tabular}

Keterangan : TN ; Tidak Nyata

Hst ; Hari Setelah Tanam 
Agustinus : Pengaruh bahan organik kirinyu (Chromolaena Odorata)

Tabel 4.2 Rerata Bobot Basah Tanaman Sawi akibat Pemberian Bahan Organik Kirinyu Pada Saat Pan

Variabel

Berat Basah Tanaman Sampel dalam

Satuan Luas $\left(\mathrm{g} \mathrm{tan}^{-1}\right)$

Bobot Basah

\begin{tabular}{rr}
\hline BO0 & $18,00 \mathrm{TN}$ \\
BO1 & $19,00 \mathrm{TN}$ \\
BO2 & $19,37 \mathrm{TN}$ \\
BO3 & $20,67 \mathrm{TN}$ \\
BO4 & $20,67 \mathrm{TN}$ \\
\hline Keterangan : TN ; Tidak Nyata & \\
Hst ; Hari Setelah Tanam &
\end{tabular}

Berdasarkan hasil analisis sidik ragam menunjukkan bahwa bobot basah tanaman sawi tidak memberikan pengaruh nyata, karena pada tanaman sawi tersebut dilihat dari parameter pertumbuhan tidak memberikan hasil yang maksimal yakni pada daun, dimana kita tahu daun merupakan organ penting dari tumbuh - tumbuhan yang berfungsi sebagai penangkap energi dari cahaya mata hari melalui fotosintesis, ialah suatu proses biokimia pembentukan zat makanan atau energi yaitu glukosa yang dilakukan tumbuhan dengan menggunakan zat hara, karbondioksida, dan air serta dibutuhkan bantuan energi cahaya matahari. Anonim,(2011) hal ini juga didukung dengan luas daun tanaman, sedangkan luas daun tanaman sawi dalam penelitian ini sangat kecil sehingga berpengaruh pada proses fotosintesis yang kemudian menghasilkan zat makanan yang tidak optimal sehingga tidak terpenuhi kebutuhan makanan oleh tanaman itu sendiri guna menopang proses pertumbuhan dan perkembangan tanaman tersebut. Anonim,(2011).

Tabel 4.3 Hasil Analisis Tanah Awal di Kawasan Agroforestry BTNK Ende, Pada Lab. Jurusan Ilmu Tanah, Universitas Brawijaya Malang (2010)

\begin{tabular}{|c|c|c|c|c|c|c|c|c|c|}
\hline \multirow[t]{2}{*}{ No Lab } & \multirow[t]{2}{*}{ Kode } & \multicolumn{2}{|c|}{$\mathrm{pH} 1: 1$} & C.organik & \multirow[t]{2}{*}{ N.total } & \multirow[t]{2}{*}{$\mathrm{C} / \mathrm{N}$} & \multirow{2}{*}{$\begin{array}{l}\begin{array}{l}\text { Bahan } \\
\text { Organik }\end{array} \\
\ldots \ldots \% \ldots\end{array}$} & \multirow{2}{*}{$\begin{array}{r}\text { P.Olsen } \\
\ldots . . . \mathrm{N}\end{array}$} & \multirow{2}{*}{$\frac{\text { Bray } 1}{\mathrm{~kg}-1 \ldots .}$} \\
\hline & & $\mathrm{H} 2 \mathrm{O}$ & KCL1N & $\ldots \ldots$ & & & & & \\
\hline TNH 472 & A1 & 6,7 & 5,7 & 2,94 & 0,38 & 8 & 5,08 & 4,27 & - \\
\hline TNH 473 & $\mathrm{~A} 2$ & 6,6 & 5,5 & 3,44 & 0,41 & 8 & 5,95 & 9,08 & - \\
\hline TNH 474 & A3 & 6,3 & 5,3 & 2,81 & 0,36 & 8 & 4,87 & - & 5,88 \\
\hline TNH 475 & A4 & 6,3 & 5,3 & 2,82 & 0,34 & 8 & 4,88 & - & 7,51 \\
\hline Rerata & & 6,4 & 5,45 & 3 & 0,37 & 8 & 5,19 & 6,675 & 6,695 \\
\hline Kategori & & & & $S$ & $S$ & $\mathrm{R}$ & $\mathrm{T}$ & SR & SR \\
\hline
\end{tabular}

Ketangan :T ; Tinggi, S ; Sedang, R ; Rendah, SR ; Sangat Rendah 
Tabel 4.4 Hasil Analisis Tanah Akhir di Kawasan Agroforestry BTNK Ende, Pada Lab. Jurusan Ilmu Tanah, Universitas Brawijaya Malang (2010)

\begin{tabular}{|c|c|c|c|c|c|c|c|}
\hline No Lab & Kode & $\mathrm{C}-$ organic & N. Total & $\mathrm{C} / \mathrm{N}$ & an Oanik & P. Bray $1 \mathrm{~K}$ & \\
\hline & & &..$\% \ldots$ & 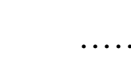 & to......... & $\mathrm{Mg} \mathrm{Kg}-1$ & $\begin{array}{c}\text { NH4OAC1N } \\
\text { pH:7 }\end{array}$ \\
\hline TNH1135 & K0 & $2,89 \mathrm{~S}$ & $0,29 \mathrm{~S}$ & $10 \mathrm{R}$ & $5,28 \mathrm{~T}$ & $15,89 \mathrm{~S}$ & $0,40 \mathrm{~S}$ \\
\hline TNH1136 & $\mathrm{K} 1$ & $3,05 \mathrm{~S}$ & $0,29 \mathrm{~S}$ & $10 \mathrm{R}$ & $5,28 \mathrm{~T}$ & $19,64 \mathrm{~S}$ & $0,28 \mathrm{~S}$ \\
\hline TNH1137 & $\mathrm{K} 2$ & $3,14 \mathrm{~T}$ & $0,29 \mathrm{~S}$ & $10 \mathrm{R}$ & $5,28 \mathrm{~T}$ & $22,79 \mathrm{~S}$ & $0,40 \mathrm{~S}$ \\
\hline TNH1138 & K3 & $3,15 \mathrm{~T}$ & $0,30 \mathrm{~S}$ & $10 \mathrm{R}$ & $5,46 \mathrm{~T}$ & $31,42 \mathrm{~S}$ & $0,37 \mathrm{~S}$ \\
\hline TNH1139 & K4 & $3,16 \mathrm{~T}$ & $0,30 \mathrm{~S}$ & $10 \mathrm{R}$ & $5,47 \mathrm{~T}$ & $20,55 \mathrm{~S}$ & $0,43 \mathrm{~S}$ \\
\hline
\end{tabular}

Ketangan :T ; Tinggi, S ; Sedang, R ;

Rendah

Hasil penelitian menunjukan bahwa pemberian BahanOrganik Kirinyu dapat meningkatkan kandungan $\mathrm{C}$ - Organik tanah padaperlakuan 20 ton/ha.adalah 3,16 \% (kategori tinggi) dibandingkan dengan kondisi awal tanah sebelum diaplikasikan bahan organik kirinyu keadaan C - Organik tanah pada lokasi penelitian adalah 3,00 $\%$ (kategori sedang) dan kandungan Bahan Organik Tanah juga meningkat pada perlakuan 20 ton/ha. adalah 5,47 $\%$ sedangkan sebelum diaplikasikan bahan organik kirinyu keadaan bahan organik tanah pada lokasi penelitian adalah 5,19\%. Hal ini menunjukan bahwa pemberian bahan organik kirinyu memberikan perubahan sifat-sifat tanah, yaitu sifat kimia tanah (Anonim 2010), Bahan organik merupakan pembentuk granulasi dalam tanah dan sangat penting dalam pembentukan agregat tanah yang stabil.Bahan organik berperan sebagai penambah hara $\mathrm{N}, \mathrm{P}, \mathrm{K}$ bagi tanaman dari hasil dekomposisi oleh mikroorganisme (Anonim, 2010)

Jenis tanah yang berada pada lokasi penelitian adalah, jenis tanah lempung berpasir (Balai Taman Nasional Kelimutu, 2010), sifat - sifat tanah berpasir yakni : kemampuan menahan air sangat rendah, kemampuan menyimpan unsur hara sangat kecil, dan airasinya baik (Anonim, 2010), maka dengan keadaan tanah seperti ini dilakukannya penelitian dengan pemanfaatan bahan organik kirinyu guna meningkatkan unsur hara sehingga menjadi subur dan keadaan tanah menjadi lempung dengan sifatnya antara lain : kemampuan menyimpan air dan tata udara menjadi baik, mengandung unsur hara yang cukup, serta tidak terlalu lekat dan keras sehingga mudah diolah (Anonym,2010). Dengan demikian pemberian Bahan Organik yang sumbernya dari Kirinyu dapat dikatakan meningkat kesuburan tanah yang dapat dilihat dari nilai $\mathrm{C}$ Organik dan Bahan Organik tanah setelah diaplikasikan Bahan Organik Kirinyu.

\section{SIMPULAN}

Berdasarkan hasil penelitian, maka dapat disimpulkan hasil penelitian sebagai berikut :

1. Pemberian bahan organik kirinyu terhadap tanaman Sawi Brasica juncea tidak memberikan pengaruh yang nyatapada Tinggi tanaman, Jumlah Daun, Luas Daun, dan Bobot Basah Tanaman Sawi pada berbagai umur pengamatan dikarenakan Bahan Organik belum terdekomposisi secara sempurna

2. Bahan Organik Kirinyu 20 ton/ha dapat meningkatkan Kandungan C- organik 
tanah, dari 3,00 menjadi 3,16\% dan Bahan Organik tanah dari 5,19 menjadi 5,47\%.

\section{UCAPAN TERIMA KASIH}

Pada kesempatan ini penulis ingin mengucapkan terima kasih kepada semua pihak yang telah membantu dengan caranya masing-masing dalam melengkapi tulisan ini.

\section{DAFTAR PUSTAKA}

Anonim(2008)KhasiatSawihttp://id.ans wers.ya

hoo.com/question/index?qid=20 080306030907AAFGBam disidir15-05-2010

Anonim(2010)PerananBahanOrganikB agitanamanhttp://webcache.goog leusercontent.com/search?q=cac he:8p31rz1i4RQJ:www.situshija u.co.id/tulisan.php\%3Fact\%3Dd etail\%26id\%3D41\%26id_kolom $\% 3 \mathrm{D} 2+$ peranan+bahan+organik + terhadap+pertumbuhan + dan $+h$ asil+tanaman\&cd=19\&hl=id\&ct $=\mathrm{clnk} \& \mathrm{gl}=\mathrm{id}$ disidir15-05-2010

Anonim(2010)AplikasiPupukHijauChr omolaenaodoratadanTithoniadiv ersifolia Pada Pergiliran Tanaman Sayuran Daun di Desa Sobokerto, Kabupaten BoyolaliPardonohttp://www.find pdf.com/carikandungan+sawi+hi jau.html disidir 11-05-2010

Anonim(2011)://webcache.googleeuser contet.com/search?q=cache:rG3 DwZpWV

A8J:www.tanamanair.com/page _artikel/aquascape_umum.html+ PROSES+FOTOSINTESIS+TA NAMAN\&cd $=18 \& \mathrm{hl}=\mathrm{id} \& \mathrm{ct}=\mathrm{cl}$ $\mathrm{nk} \& \mathrm{gl}=\mathrm{id} \& \mathrm{client}=$ firefox $-\mathrm{a}$ disidir 11-05-2011

AtmojoSuntoroWongso,2007,Mencari SumberPupukOrganikhttp://sunt oro.staff.uns.ac.id/files/2009/04/ 26-mencari-sumber-pupukorganik.docdisidir11-05-2010

BalaiTamanNasionalKelimuhttp://ww w.dephut.go.id/INFORMASI/T No/o 20IN DOENGLISH/tn_kelimutu.htm disidir 05-11-2010

Gomez A. Kwanchai dan Gomez A. Arturo. 1995 Prosedur Statistik Untuk Penelitian Pertanian Edisi 2. Universitas Indonesia, Jakarta.

KardinDardjat ( $2011 \quad)$ http://webcache.googleuserconte nt.com/search?q=cache:qHBo6O sEY-

qgJ:diperta.jabarprov.go.id/assets /data/arsip/Teknologi_Kompos.d ocx+berapa+lama+proses+dekom posi-

si-

si+bahan+organik+berlangsung \& $\mathrm{hl}=\mathrm{id} \& \mathrm{gl}=\mathrm{id}$ disidir 10-05-2011

Kurnianto.M.2008Menujupertanianyang ramahling-

kunganhttp://www.Greenmining.i nfo/detail.php? $\mathrm{x}=$ reklamasi $\& \mathrm{y}=\mathrm{fe}$ 8fc3d9f5932a8434ee77c2a7b567

09disidir Maret 2008)

Kurnianto.M.2008www.google.com//isr oi.kompos_dan_proses_pengomp osan disidir Maret 2008)

Nazarudin.2003.Budidaya dan pengaturan panen sayuran dataran rendah, PT. Penebar Swadaya, Jakarta.

MargiantoEko,2007.BudidayaTanaman Sawi.htt://zuldesains.wordpress.c om/ 2008/01/11/budidayatanaman-sawi/. disidir Maret 2008)

Purba.2009.UjiEfektivitasBeberapaWak tuAplikasiPupukHijauKirinyu(Ch romolaenaodoratal)TerhadapPert umbuhandanProduksiJagung(Zea Mays).http://respository.usu.ac.id /bitstream/123456789/7570/1/09 E 01229.pdf 